\title{
Prevalence of blindness and visual impairment in Atakunmosa West Local Government Area of southwestern Nigeria
}

\author{
O.H. ONAKPOYA ${ }^{1 *}$, A.O. ADEOYE ${ }^{1}$, F.B. AKINSOLA ${ }^{2}$ and B.O. ADEGBEHINGBE ${ }^{1}$ \\ ${ }^{1}$ Department of Surgery, Obafemi Awolowo University Teaching Hospitals Complex, PMB 5538, IIe Ife, \\ Osun State, Nigeria \\ ${ }^{2}$ Guinness Eye Center, Lagos University Teaching Hospital, Idi Araba, Lagos, Nigeria
}

\begin{abstract}
Blindness survey remains a useful tool for eye care needs assessment. A cross sectional survey of Atakunmosa West Local Government Area, a rural community of southwest Nigeria with no form of eye care facility was carried out. The objective of this study was to define areas of eye care need and develop programme for elimination of avoidable blindness in the region. Multistage cluster sampling technique selected 1,248 respondents across all the eleven health districts. Respondents had visual acuity and ocular examination. Blindness was defined as presenting visual acuity (pva) of $<3 / 60$ in the better eye and visual impairment as pva of $<6 / 18$ in the better eye. Out of the 1,248 respondents screened, $14(1.1 \%)$ were blind and 78 $(6.3 \%)$ were visually impaired. There was an increasing risk of blindness and visual impairment with age; occurring more commonly after 60 years of age. The prevalence of blindness and visual impairment were higher in females although not statistically significant $(P=0.70 ; 0.46$ respectively). Blindness was caused mainly by cataract $(57.2 \%)$, glaucoma $(14.3 \%)$ and congenital childhood blindness $(14.3 \%)$. Cataract $(57.7 \%)$, glaucoma $(16.7 \%)$ and uncorrected refractive error $(15.4 \%)$ were the leading causes of visual impairment. Blindness was avoidable in $85.7 \%$ of cases. Qualitative and subsidised cataract surgical and refractive services are needed urgently in this region and therefore, the incorporation of eye health care into the existing primary health care system may ensure programme sustainability.
\end{abstract}

Key words: blindness, cataract, glaucoma, acuity, visual impairment, Nigeria

\section{Introduction}

Globally, 37 million persons are estimated to be blind and 124 million visually impaired (Resnikoff et al., 2004). Asia and Africa bear 75\% of the global burden of blindness with up to $80 \%$ of the causes of blindness being avoidable (WHO, 1979; Thylefos, 1991; Annon, 2003). The global initiative for elimination of avoidable blindness (Vision 2020 "The Right to Sight") was launched in 1999 to eliminate avoidable blindness world wide (Annon, 2003). The prevalence and causes of blindness vary in different countries and even within the same country, regional variations do exist (Thylefor et al., 1995). A nation-wide blindness survey programme is on going in Nigeria. Prior to this, various researchers had reported blindness prevalence rates of between 0.9 and 1.3\% (Adeoye, 1996; Gilbert, 2001; Gilbert \& Foster, 2001; Rabiu, 2001; Farber, 2003) in different regions of the country.

Survey of blindness remains a useful tool for the assessment of eye care needs of a community and is recommended as a platform for developing programmes for elimination of avoidable blindness (WHO, 1980; Kuper et al., 2006). Regional surveys ensure that large variations are not lost in averages calculated for national data (Khandekar et al., 2002; Adeoye,
1996) and encourage the 'piece by piece' regional approach of district level Vision 2020 (Cook \& Quereshi, 2005). In view of this, blindness survey of Atakunmosa West Local Government Area in southwest Nigeria was carried out to define areas of eye care need and recommend modalities for the regional elimination of avoidable blindness.

\section{Materials and Methods}

\section{Study area}

A descriptive cross sectional study was carried out in Atakunmosa West Local Government Area in Osun State, southwestern Nigeria. The population of the area is estimated at 86,360 (NPC, 1991). It is a rural, largely agrarian region with 11 health districts. It has a well organized Primary Health Care (PHC) network led by a general duty medical doctor and assisted by nurses and community health extension workers. None of these health personnel has had any form of training in eye health care. There are no statutory, mobile or outreach eye care centres within the region. The distance of the constituent communities to the nearest eye care facilities (Wesley Guild Hospital-WGH in Ilesa or Obafemi Awolowo University Teaching Hospitals' Complex-OAUTHC in Ile Ife) ranges from $20-120 \mathrm{~km}$. 


\section{Study design}

A multistage cluster sampling technique was employed in the final selection of respondents across all the eleven health districts. Three communities each were randomly selected from each district based on the list used for door to door Expanded Programme on Immunization for the region. A community consisted of a named well designated area within a town or a whole small village. A cluster made up of 7-9 households were selected in each community to make up 37-40 consenting usual residents aged $\geq 5$ years. A minimum cluster sample size of 1,230 was calculated using the Computer Programme for Epidemiological Analysis (P.M. Gahlinger \& J.H. Abramson Statistical Software 1993-2000) with an estimated blindness prevalence of $0.91 \%$ (Adeoye, 1996) at 95\% confidence level and 0.5\% maximum acceptance difference.

The presenting visual acuity (pva) was assessed using the Snellen's or illiterate E chart for each eye depending on the level of literacy of the respondent. This was placed six metres away in an open space in daylight. The last completed line on the chart was recorded as the visual acuity for that eye. Individuals with pva $<6 / 18$ were crosschecked and further tested with pinhole or $+10 D S$ lens. Persons who could not read the 6/60 line were further tested with the chart placed at $3 \mathrm{~m}$, counting fingers, hand movement and ability to perceive light. The respondents had ocular examination within the house using pen torch, direct ophthalmoscope and Perkins hand-held tonometer to determine the cause of blindness and visual impairment. They were then counselled and referred to the eye clinics of WGH and OAUTHC for management. Intraocular pressure above $22 \mathrm{mmHg}$ was taken as abnormal and cup/disc ratio above 0.6 was considered glaucomatous. Blindness was defined as a pva of $<3 / 60$ in the better eye while visual impairment was pva of $<6 / 18$ in the better eye. Couching refers to the dislocation of the cataractous lens into the vitreous by traditional eye doctors. The survey team was made up of an ophthalmologist and two community health extension workers who had been trained and standardized for the study. A local guide was included in every community surveyed.

\section{Data analysis}

Data were recorded and analyzed using the SPSS version 11 . Analysis of categorized variables was done with tests of significance and statistical significance inferred at $P<0.05$.

\section{Ethical consideration}

Ethical clearance for the survey was obtained from the ethical committee of the OAUTHC. Written consent from the PHC coordinator of AWLGA and verbal consent from the community heads of selected communities were also obtained. Informed consent of the household head and participating individuals were obtained at the time of survey.

\section{Results}

A total of 1,248 respondents participated in the study. The age range was 5-120 years with an average of 32.8 (SD 22) years. Persons aged $\geq 50$ years made up to $23 \%$ of the sample population. There were $598(47.9 \%)$ males and $650(52.1 \%)$ females with a male to female ratio of 1:1.1. The gender difference of the study population was not statistically significant $(P=$ $0.76)$.

Table 1: Visual acuity in the better eye of sample population

\begin{tabular}{lcc}
\hline Visual acuity & Frequency & Percent \\
\hline $6 / 4-6 / 18$ & 1156 & 92.6 \\
$<6 / 18-6 / 60$ & 68 & 5.5 \\
$<6 / 60-3 / 60$ & 10 & 0.8 \\
$<3 / 60-N P L$ & 14 & 1.1 \\
Total & $\mathbf{1 2 4 8}$ & 100 \\
\hline
\end{tabular}

A total of 1156 (92.6\%) had pva of $6 / 18$ or better (Table 1). Bilateral blindness was recorded in $14(1.1 \%)$ of the respondents while $24(1.9 \%)$ were unilaterally blind and $78(6.3 \%)$ had visual impairment (Table 2). The blindness prevalence in males was $1.0 \%$ and in females $1.2 \%$ with a male: female ratio of 1:1.3. This gender difference was not statistically significant $(P=0.70)$. There were also more females amongst the visually impaired $(P=0.46)$. Fifteen $(62.5 \%)$ of the unilaterally blind persons were males. 
Table 2: Age distribution of blindness and visual impairment

\begin{tabular}{lcrcc}
\hline Age group (years) & Number & $\begin{array}{r}\text { Unilateral blindness } \\
(\%)\end{array}$ & $\begin{array}{c}\text { Bilateral blindness } \\
(\%)\end{array}$ & $\begin{array}{c}\text { Visual Impairment } \\
(\%)\end{array}$ \\
\hline$<10$ & 115 & 0 & $1(0.9)$ & 0 \\
$10-19$ & 341 & 0 & $1(0.3)$ & $1(0.3)$ \\
$20-29$ & 212 & $1(0.5)$ & 0 & $4(1.9)$ \\
$30-39$ & 144 & 0 & 0 & $2(1.4)$ \\
$40-49$ & 149 & $2(1.3)$ & 0 & $2(1.3)$ \\
$50-59$ & 78 & $3(3.9)$ & 0 & $8(10.3)$ \\
$60-69$ & 93 & $5(5.4)$ & $3(3.2)$ & $19(20.4)$ \\
$70-79$ & 68 & $5(7.4)$ & $3(4.4)$ & $21(30.9)$ \\
$>80$ & 48 & $8(16.7)$ & $6(12.5)$ & $21(43.5)$ \\
Total & $\mathbf{1 2 4 8}$ & $\mathbf{2 4}(\mathbf{1 . 9 )}$ & $\mathbf{1 4}(\mathbf{1 . 1})$ & $\mathbf{7 8}(6.3)$ \\
\hline
\end{tabular}

There was an increased risk of blindness and visual impairment with age. The prevalence of blindness in persons $\geq 60$ years was $5.74 \%$. Over $85 \%$ of blindness and $78 \%$ of visual impairment were recorded in persons aged $\geq 60$ years. The mean age for bilateral blindness was $72.1 \pm 31$ years and $61 \pm 18.3$ years for visual impairment (Table 2).

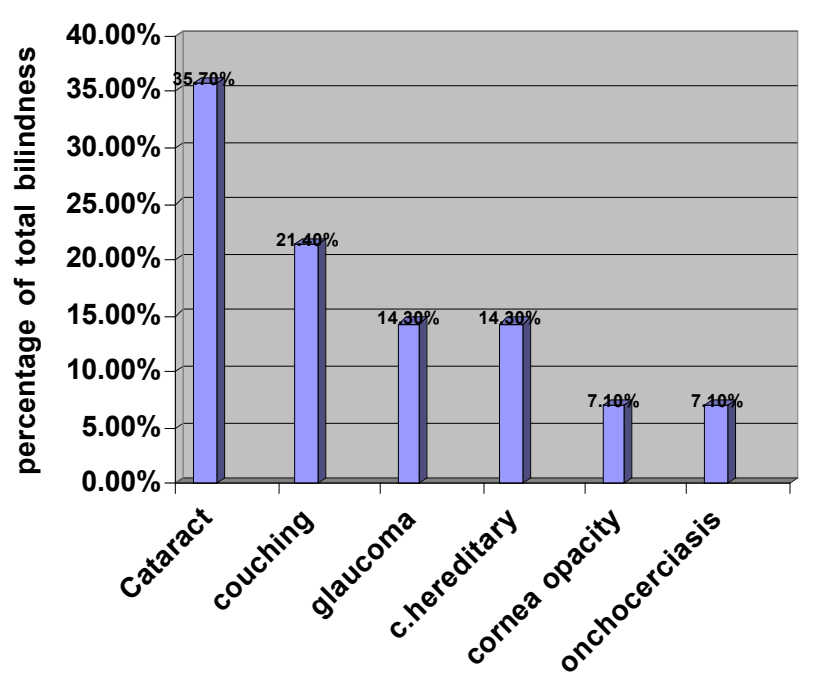

Figure 1: Causes of blindness in percentages

Cataract and couching $(57.1 \%)$, glaucoma $(14.3 \%)$ and congenital hereditary childhood blindness were the leading causes of blindness recorded (Figure 1). Unilateral blindness was mainly due to cataract $(37.5 \%)$, trauma (25\%) and glaucoma $(12.5 \%)$ (Figure 2).

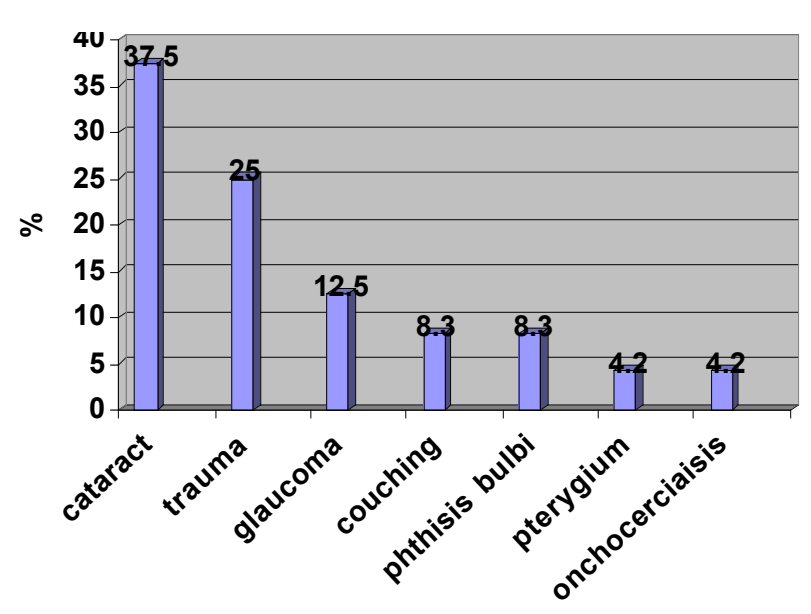

Figure 2: Causes of unilateral blindness

The main causes of visual impairment in this region were cataract $(57.7 \%)$, glaucoma $(16.7 \%)$ and uncorrected refractive error (15.4\%) (Figure 3). Over four-fifths ( $85.7 \%$ ) of bilateral blindness and $94.8 \%$ of visual impairment were avoidable in the region.

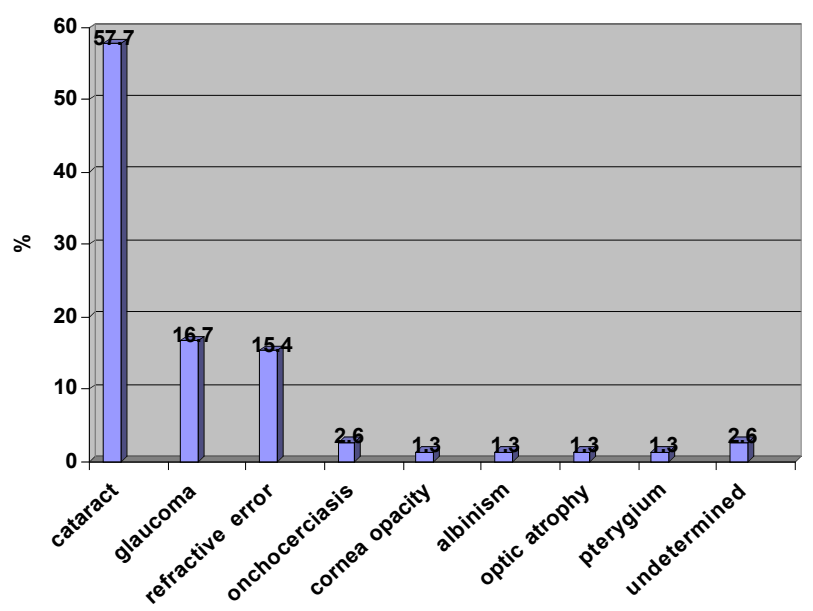

Figure 3: Causes of visual impairment 


\section{Discussion}

Individuals aged 50 years and above constituted $23 \%$ of sample population which is lower than the $33 \%$ and $44 \%$ (Ajibode, 1999; Oluleye, 2004) reported in other rural communities of southwestern Nigeria during similar surveys. The young adults in this region are mainly large scale cocoa farmers necessitating their living in the region while occasionally travelling to larger cities. This is unlike the rural-urban drift reported in the other surveys (Ajibode, 1999; Oluleye, 2004).

The blindness prevalence rate of $1.1 \%$ is of public health significance in this region. This figure is close to the $1.3 \%$ estimate provided by the secretariat of Nigeria's National Programme for Prevention of Blindness from compilation of different regional surveys. It is however higher than the $0.91 \%$ reported in a similar study conducted in a single ward of neighbouring Ife North Local Government Area (Adeoye, 1996) which may be due to the relatively homogenous smaller ward studied. It is also higher than the rate reported in the neighbouring Oyo State of southwestern Nigeria; the area surveyed had enjoyed previous eye screening exercises and has a health centre which is an outreach centre of a tertiary eye care centre (Oluleye, 2004). The prevalence of blindness recorded in this study is higher than the $0.7 \%$ of reported in the Gambia (Faal et al., 1989) but much lower than the $2.47 \%$ in the neighbouring country of Togo (Balo et al., 2000).

The degree of visual impairment elicited is close to six times that of blindness. These persons are at risk of blindness in future if there is no eye care intervention thus increasing the blindness rate. The $6.3 \%$ rate is higher than the $2.5 \%$ and $5 \%$ reported for the rural communities of Ogun (Ajibode, 1999) and Delta (Patrick-Ferife et al,. 2005) states of Nigeria.

Blindness was 1.3 times more common in females as previously reported by other authors (Faal et al., 1989; Negrel et al., 1990; Fafowora, 1996; Bucher \& Ijsselmiuden, 1998; Balo et al., 2000; Dandona et al., 2002;). The rate of visual impairment was also higher in females. The gender issue in blindness affirms that blindness occurs more in females and especially in the developing countries. Females utilize eye care facilities much less than males. This is thought to be due to their lower socio-economic status and financial dependence.

There was a worsening risk of blindness with increasing age similar to report by various authors (Ajibode, 1999; Abdul, 2002; Balo et al., 2000; Fafowora, 1996; Fasina \& Ajayeoba, 2003.) Persons aged $\geq 60$ years constituted $75 \%$ of the blind in this survey comparing favourably with findings of others (Adeoye, 1996; Ajibode, 1999; Patrick-Ferife et al., 2005; Fafowora, 1996). Increasing age remains a major risk factor for developing blindness since most blinding eye diseases are age related (Adeoye, 1996; Ajibode, 1999; Abdul, 2002; Patrick-Ferife et al., 2005; Negrel et al., 1990; Fafowora, 1996; Wormald, 1995). The proposal of the rapid blindness survey of persons aged 50 years and above is further supported since this has been found to be a good indicator for the prevalence and causes of blindness and visual impairment in the total population (Kuper et al., 2006; Dineen et al., 2006). Its usefulness in determination of avoidable blindness is beneficial for blindness prevention eye care programme planning (Dineen et al., 2006.) The childhood blindness of 5.5/1000 recorded in this study is rather high compared to the $1.0 / 1000$ expected for a country like Nigeria (Gilbert, 2001). This rate however should be interpreted with caution because a large number of children need to be screened to give the true representation of prevalence and pattern of childhood blindness in a given community (Gilbert \& Foster, 2001).

The major causes of blindness and visual impairment found are similar to reports in the developing countries (Adeoye, 1996; Ajibode, 1999; Oluleye, 2004) with cataract, glaucoma and hereditary congenital eye disease taking the lead. Cataract, glaucoma and uncorrected refractive error were the commonest cause of visual impairment encountered in this study. Thus, the provision of cataract surgical services to the needy in this region is expected to reduce the prevalence of blindness by $57.2 \%$.

Cataract backlog is doubtless a significant problem in this area considering that $57.7 \%$ of persons with visual impairment suffer from visually disabling cataract. Glaucoma remains a challenging disease and more so in this populace of Atakunmosa West Local Government, ranking as the second leading cause both of blindness and visual impairment. 
Notably, the accurate quantification of the contribution of glaucoma blindness and visual impairment may have been underestimated in this study since visual field analysis was excluded in the ocular examination. All childhood blindness reported occurred in a single family with suspected Leber's Congenital Amaurosis. Further electrophysiological and molecular studies of the children and members of their family would have aided specific diagnosis; these are however not presently available in this environment.

Uncorrected refractive error was responsible for $15.4 \%$ of visual impairment. Using the pva as against the best corrected visual acuity in the definition of visual impairment in this survey ensured that the contribution of uncorrected refractive error to visual impairment was not neglected (Dandona et al., 2002). However, it should be noted that the real burden of refractive error may have been underestimated as persons with uncorrected refractive errors who had visual acuity $6 / 18$ and below were excluded by the methodology.

Like in many other Nigerian communities, the main causes of blindness in this region were largely avoidable. The major actions needed for the study community can be deduced from the causes of blindness and visual impairment found. An eye care programme incorporated into the existing primary health structure will be cheaper and may ensure sustainability. Qualitative and subsidised cataract and glaucoma surgical services should be made available to this region as well as the provision of refraction services. Effective advocacy will stimulate government's political will to extend eye care delivery to the rural populace.

\section{Acknowledgements}

The management of the Obafemi Awolowo University Teaching Hospitals Complex, Ile Ife provided grants for part funding of the survey.

\section{References}

Abdul, L. (2002) Prevalence and causes of blindness and low vision in Danbatta Local Government Area, Kano state Nigeria. Nigerian Medical Journal 11, 108-112.

Adeoye, A. (1996) Survey of blindness in south- western Nigeria. Tropical Medicine and International Health 1, 672-676.

Ajibode, H.A. (1999) The prevalence of blindness and visual impairment in Ikenne Local Government Area of Ogun State Nigeria. Nigerian Journal of Ophthalmology 7, 2327.

Annon (2003) The resolution of World Health Assembly on the Elimination of Avoidable Blindness. Community Eye Health Journal 16, 17-18.

Balo, P.K., Wabagira, J., Banla, M. \& Kuaovi, R.K. (2000) Specific causes of blindness and visual impairment in a rural area of southern Togo. Journal Francais d'Optalmologie 23, 459-464.

Bucher, P.J.M. \& Ijsselmiuden, C.B. (1998) Prevalence and causes of blindness in Northern Transvaal. British Journal of Ophthalmology 72, 721-726.

Cook, C. \& Quereshi, B. (2005) Vision 2020 at the District level. Community Eye Health Journal 18, 85-87.

Dandona, R., Dandona, L., Srinivas M., Giridhar, P., Prasad, M.N., Vilas, K., McCarty, C.A. \& Rao, G.N. (2002). Moderate visual impairment in India: the Andhra Pradesh Eye Disease Study. British Journal of Ophthalmology 86,373-377.

Dineen, B., Foster, A. \& Faal, H. (2006) A proposed rapid methodology to assess the prevalent and causes of blindness and visual impairment. Ophthalmic Epidemiology 13, 31-34.

Faal, H., Minassian, D., Sowa, S. \& Foster, A. (1989) National survey of blindness and low vision in The Gambia : Results. British Journal of Ophthalmology 73, 82-87.

Fafowora, O.F. (1996) Prevalence of blindness in a rural ophthalmically underserved Nigerian community. West African Journal of Medicine 15, 228-231.

Farber, M.D. (2003) Estimation of prevalence and incidence rates and cause of blindness in Israel. Ophthalmic Epidemiology 10, 267-277.

Fasina, F.O. \& Ajayeoba, A.I. (2003) Prevalence and causes of blindness and low vision in Ogun State, Nigeria. African Journal of Biomedical Research 6, 63-67.

Gilbert, C. \& Foster, A. (2001) Childhood blindness in the context of Vision 2020: 
the right to sight. Bulletin of the World Health Organization 79, 227-232.

Gilbert, C. (2001) New issues in childhood blindness. Community Eye Health Journal 14, 53-56.

Khandekar, R., Mohammed, A.J., Negrel, A.D. \& Al Riyami, A. (2002) The prevalence and causes of blindness in the Sultanate of Oman: the Oman Eye study. British Journal of Ophthalmology 86, 957-962.

Kuper, H., Polack, S. \& Limburg, H. (2002) Rapid assessment of avoidable blindness. Community Eye Health Journal 19, 68-69.

Negrel, A.D., Massembo-Yako, B., Botaka, E., Minassian, D.C. \& Coddy-Zitsamele, R. (1990) Prevalence and causes of blindness in the Congo. Bulletin of the World Health Organization 68, 237-243.

NPC (1991) 1991 Population census of the Federal Republic of Nigeria. National Population Commission.

Oluleye, T.S. (2004) Cataract blindness and barriers to surgical intervention in three rural communities of Oyo State Nigeria. Nigerian Medical Journal 13,156-160.

Patrick-Ferife, G., Ashaye, A.O. \& Quereshi, B.M. (2005) Blindness and low vision in adults in Ozoro, a rural community in
Delta State, Nigeria. Nigerian Journal of Medicine 4, 390-395.

Rabiu, M.M. (2001) Cataract blindness and barriers to uptake of cataract surgery in a rural community in Northern Nigeria. British Journal of Ophthalmology 85, 776780.

Resnikoff, S., Pascolin, D., Etya'ale, D., Kocur, I., Pararajasegaram, R., Pokharel, G. \& Mariotti, S. (2004). Global data on visual impairment in the year 2002. Bulletin of the World Health Organization 84, 844-851.

Thylefor, B. (1991) Much blindness is avoidable. World Health Forum 12, 78-85.

Thylefor, B., Negrel, A.D., Parajasegaram, R. \& Dadzie, K.Y. (1995) Global data on blindness. Bulletin of the World Health Organization 73, 115-121.

WHO (1979) World Health Organization data on blindness throughout the world. WHO Chronicle 33, 275-283.

WHO (1980) Methods of Assessment of Avoidable Blindness. (1980). World Health Organization Offset Publication 54, 142.

Wormald, R. (1995) Editorial comment. Community Eye Health Journal 8, 11. 